-Supporting Information-

\title{
Exposure of $\mathrm{WO}_{3}$ Photoanodes to Ultraviolet Light Enhances Photoelectrochemical Water Oxidation
}

Tengfei Li, Jingfu He, Bruno Peña, Curtis P. Berlinguette*

Departments of Chemistry and Chemical \& Biological Engineering, The University of British Columbia, 2036 Main Mall, Vancouver, BC V6T1Z1. 


\section{Experimental.}

Materials. Tungsten hexachloride (99.9\%, Strem Chemicals), ethanol (99.5\%, Strem Chemicals) were used as received.

Substrate Preparations. Photoanodes of $\mathrm{WO}_{3}$ were prepared according to a previously documented spin coating thermal decomposition method. ${ }^{1}$ Tungsten hexachloride $(0.397 \mathrm{~g}, 1.00$ mmol) were added to $4.00 \mathrm{~mL}$ of ethanol. The solution was sonicated for $15 \mathrm{~min}$ and then spincoated onto an FTO substrate (TEC 15, Hartford Glass Co.) at $1000 \mathrm{rpm}$ for $30 \mathrm{~s}$. Each of the successive 6 coats was annealed at $500{ }^{\circ} \mathrm{C}$ for $10 \mathrm{~min}$, with an 8 -h annealing step at $500{ }^{\circ} \mathrm{C}$ for the last step. The UV irradiation protocol was carried out according to our pervious paper on UV curing $\mathrm{BiVO}_{4},{ }^{2}$ exposing the $\mathrm{WO}_{3}$ samples, in transparent Petri dishes sealed by parafilm, to a UV lamp (Model\# GPH436T5VH, Atlantic Ultraviolet Co.; $\lambda_{\max } \sim 254 \mathrm{~nm}$ and $185 \mathrm{~nm}$; flux $=$ $0.12 \mathrm{~mW} / \mathrm{cm}^{2}$ at $1 \mathrm{~m}$ from lamp, $\sim 10 \mathrm{~mW} / \mathrm{cm}^{2}$ at $5.5 \mathrm{~cm}$ in our experiment) for $4 \mathrm{~h}$.

Physical Methods. All PEC and photovoltage measurements were performed with a CHI 660D potentiostat in a three-electrode photoelectrochemical cell with the photoanode as the working electrode, $\mathrm{Ag} / \mathrm{AgCl}$ as the reference electrode, and a platinum wire mesh as the counter electrode. Photoelectrochemical measurements were conducted under 1 Sun simulated sunlight with an Oriel 94011A-ES solar simulator integrating a 100-W Xenon arc lamp and AM1.5 filter. Experiments were performed in $0.1 \mathrm{M}$ potassium phosphate (KPi) buffered to $\mathrm{pH} 7$, unless otherwise stated. Potentials are reported as measured vs $\mathrm{Ag} / \mathrm{AgCl}$, and adjusted to vs RHE using the Nernstian relation $\mathrm{E}_{\mathrm{RHE}}=\mathrm{E}_{\mathrm{Ag} / \mathrm{AgCl}}+0.0591 \mathrm{pH}+0.166 \mathrm{~V}$. For photocurrent measurements, linear sweep voltammetry (LSV) was used and the scan rate was maintained at $10 \mathrm{mV} / \mathrm{s}$. For charging current measurements, cyclic voltammetry (CV) were carried out in dark with scan rates of $50,100,150,200,250 \mathrm{mV} / \mathrm{s}$. Film morphologies were investigated using a Helios 
NanoLab 650 Focused Ion Beam Scanning electron microscope (SEM), with the accelerating voltage kept at $1 \mathrm{kV}$ and the current at $50 \mathrm{pA}$ for imaging. X-ray diffraction (XRD) characterization was conducted using a Bruker F8 Focus X-ray diffractometer. Data were collected between $2 \theta$ angles of $5^{\circ}$ and $90^{\circ}$ with a step size of $0.04^{\circ}$ and the step time was $0.6 \mathrm{~s}$. UV-vis data were collected with a PerkinElmer Lambda $35 \mathrm{UV} /$ Vis spectrometer with a solid sample holder accessory. Baseline scans were recorded on clean FTO. X-ray photoelectron spectroscopy (XPS) data were collected on a Leybold MAX200 spectrometer using Mg K $\alpha$ radiation. The pass energy used for the survey and narrow scans were $192 \mathrm{eV}$ and $48 \mathrm{eV}$, respectively. Atomic force microscopy (AFM) was performed in non-contact dynamic mode on Nanosurf Easy Scan 2 Atomic Force Microscope.
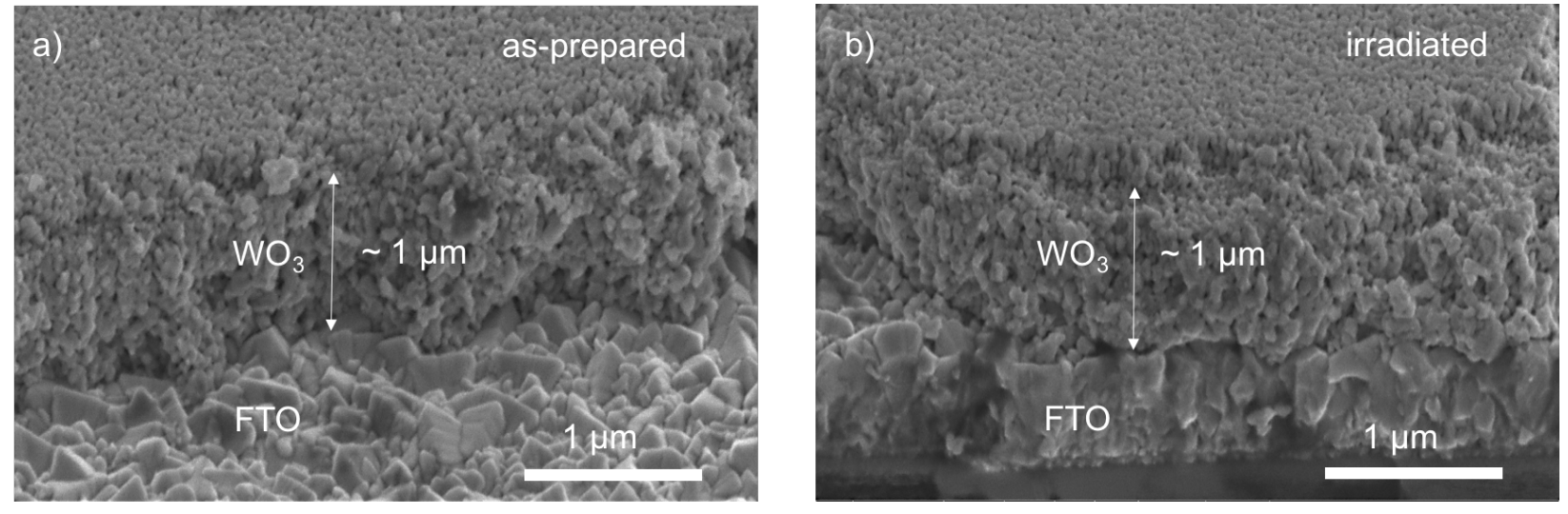

Figure S1 Cross-sectional SEM images of as-prepared (a) and irradiated (b) $\mathrm{WO}_{3}$. The thickness of the $\mathrm{WO}_{3}$ films are estimated to be around $1 \mu \mathrm{m}$. 
as prepared

a)

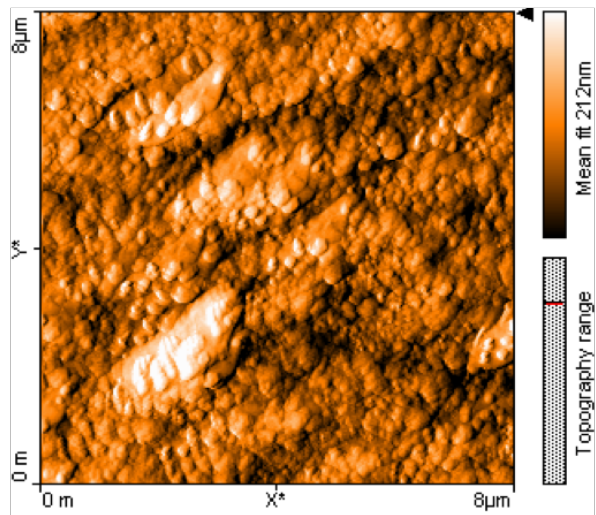

c)

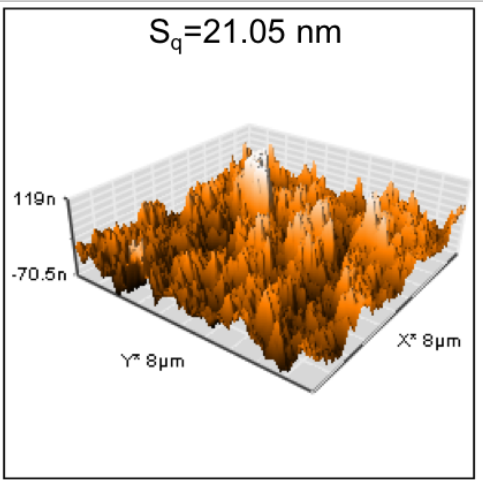

b)

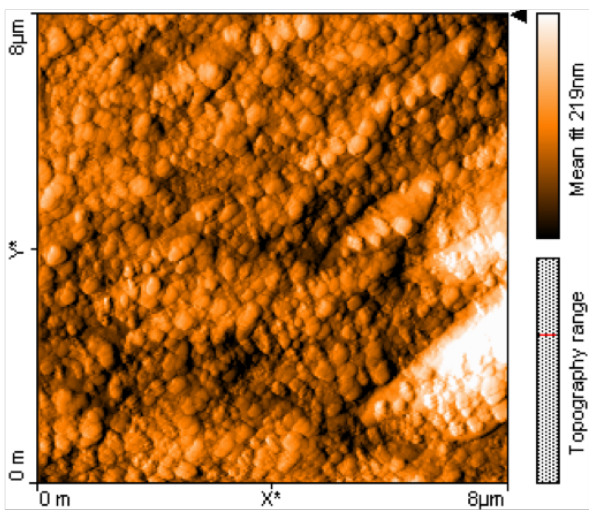

d)

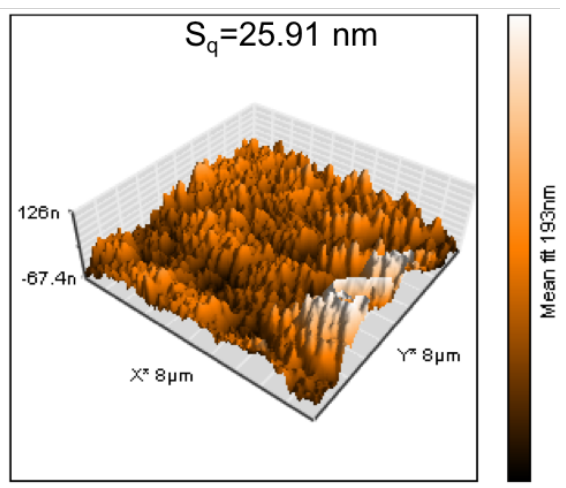

Figure S2 Plan view of AFM images of $\mathrm{WO}_{3}$ before (a) and after (b) UV irradiation. (c) and (d) show the 3D view of the same $\mathrm{WO}_{3}$ surfaces before (c) and (d) after UV irradiation, respectively, and the root mean square area roughness factors $\left(\mathrm{S}_{\mathrm{q}}\right)$ of each sample.
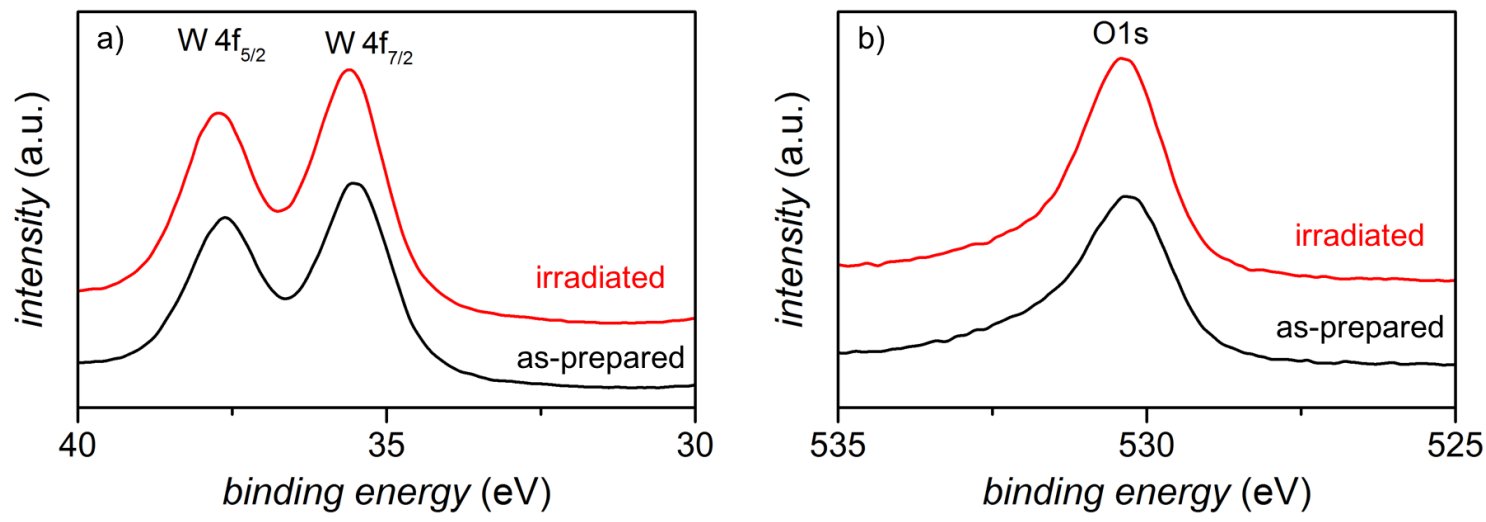

Figure S3 XPS spectra featuring the tungsten $4 f(\mathrm{a})$ and oxygen $1 s$ (b) peaks of $\mathrm{WO}_{3}$ before (black) and after (red) UV irradiation. 


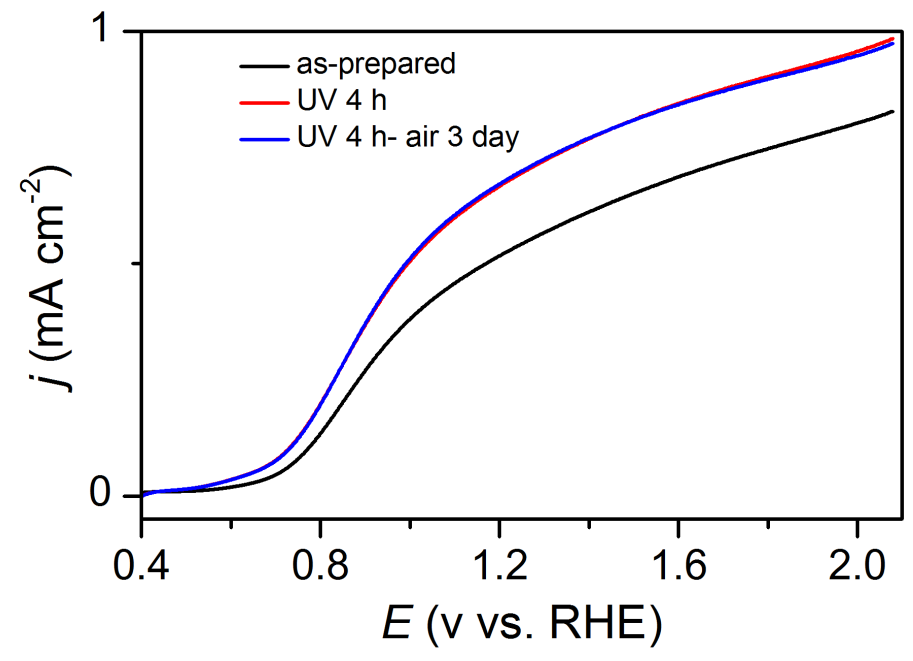

Figure S4 Photocurrent (AM1.5 front-side illumination) densities of $\mathrm{WO}_{3}$ samples before (black), after (red) $4 \mathrm{~h}$ of UV radiation, and after $4 \mathrm{~h}$ of UV irradiation then kept in air for 3 days (blue). Data were recorded in a three-electrode cell in KPi buffered solutions (pH 7).

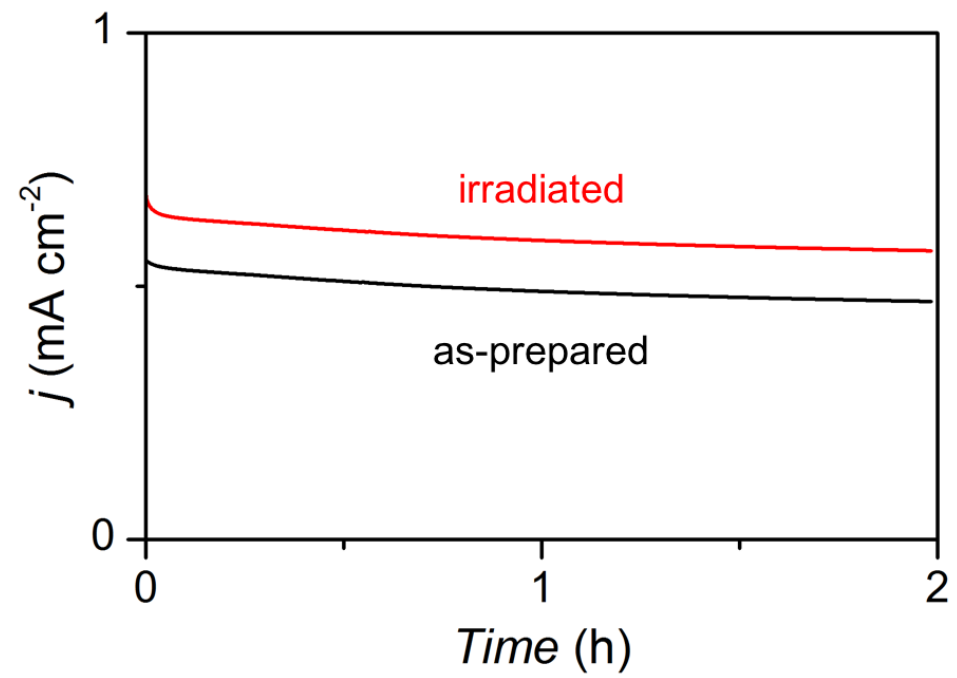

Figure S5 Anode stability at $1.23 \mathrm{~V}$ vs. RHE under $1.5 \mathrm{AM}$ illumination of $\mathrm{WO}_{3}$ before (black) and after (red) exposure to UV irradiation, measured in KPi buffered solution ( $\mathrm{pH} \mathrm{7)}$ for $2 \mathrm{~h}$. 

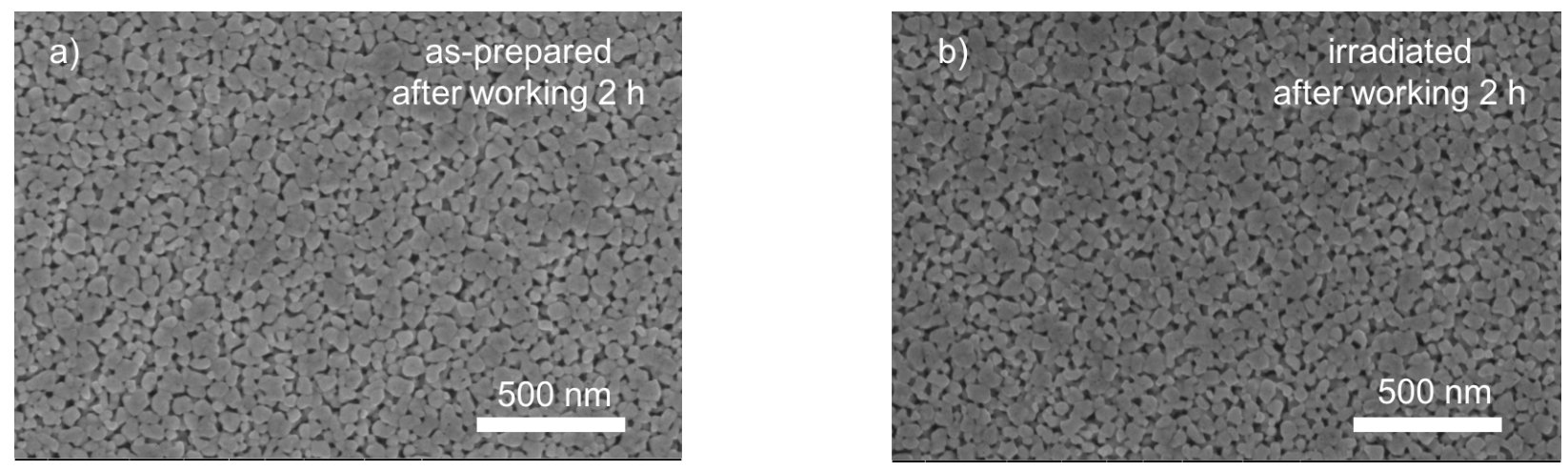

Figure S6 SEM images of as-prepared (a) and irradiated (b) $\mathrm{WO}_{3}$ after PEC working for $2 \mathrm{~h}$ at $1.23 \mathrm{~V}$ vs. RHE.

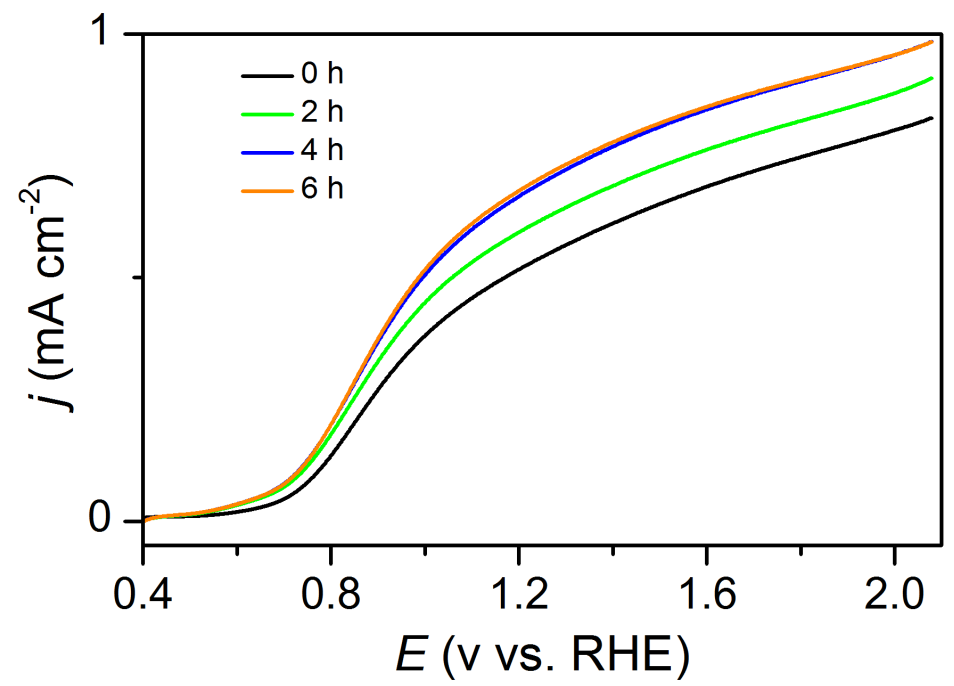

Figure S7 Photocurrent densities of $\mathrm{WO}_{3}$ photoanodes with exposure to UV radiation of 0 (black), 2 (green), 4 (blue) and 6 (orange) hours. 


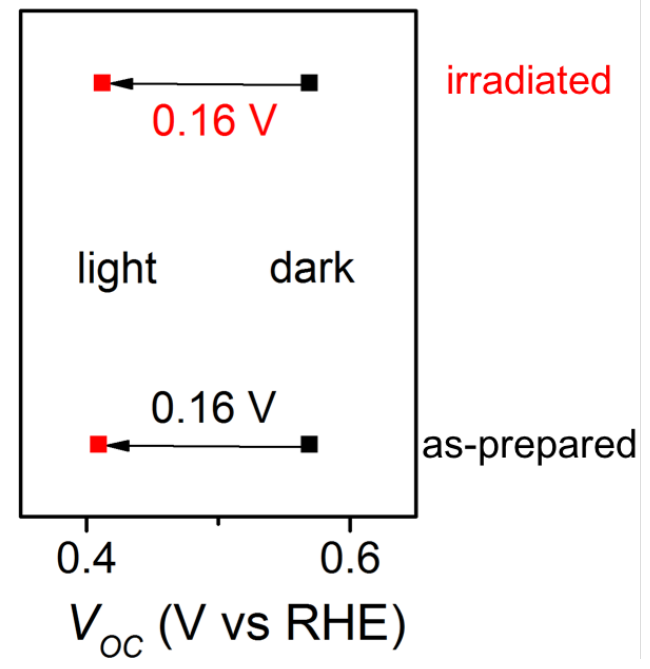

Figure S8 Open-circuit potentials $\left(\mathrm{V}_{\mathrm{OC}}\right)$, measured in the dark (black) and under AM1.5 illumination (red), of $\mathrm{WO}_{3}$ photoanodes before and after $4 \mathrm{~h}$ of $\mathrm{UV}$ irradiation. The values indicated correspond to the photovoltages generated by $\mathrm{WO}_{3}$, calculated by the difference of $\mathrm{V}_{\mathrm{OC}}$ between dark and illumination conditions.

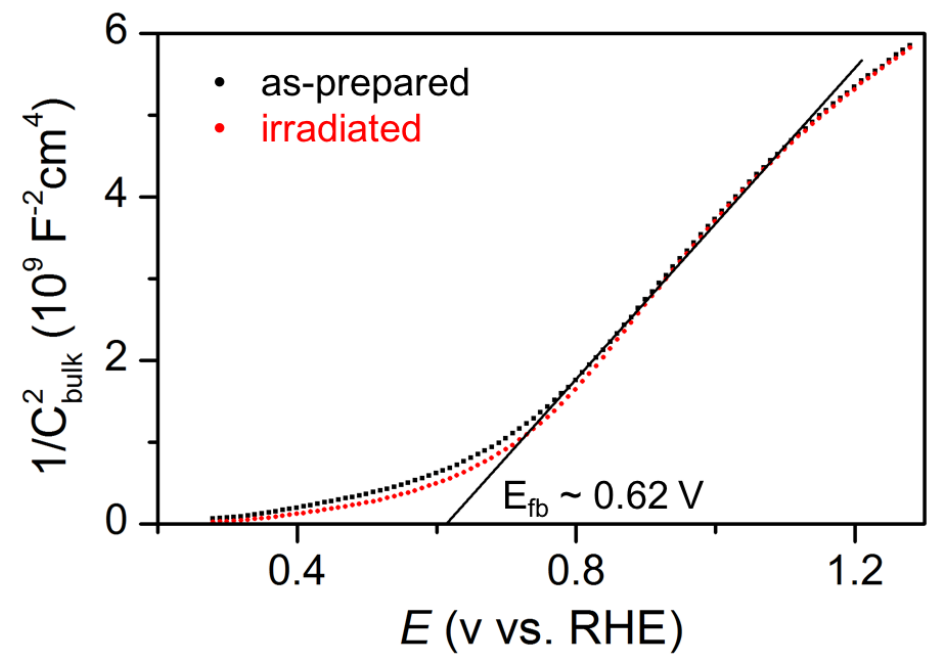

Figure S9 Mott-Schottky plots of $\mathrm{WO}_{3}$ before (black) and after (red) UV irradiation. The intercept on $\mathrm{X}$-axis represents flat band potential $\left(\mathrm{E}_{\mathrm{fb}}\right)$ around $0.61 \mathrm{~V}$ vs RHE, and the slope reveals charge carrier density around $1.0 \times 10^{20} \mathrm{~cm}^{3}$. 

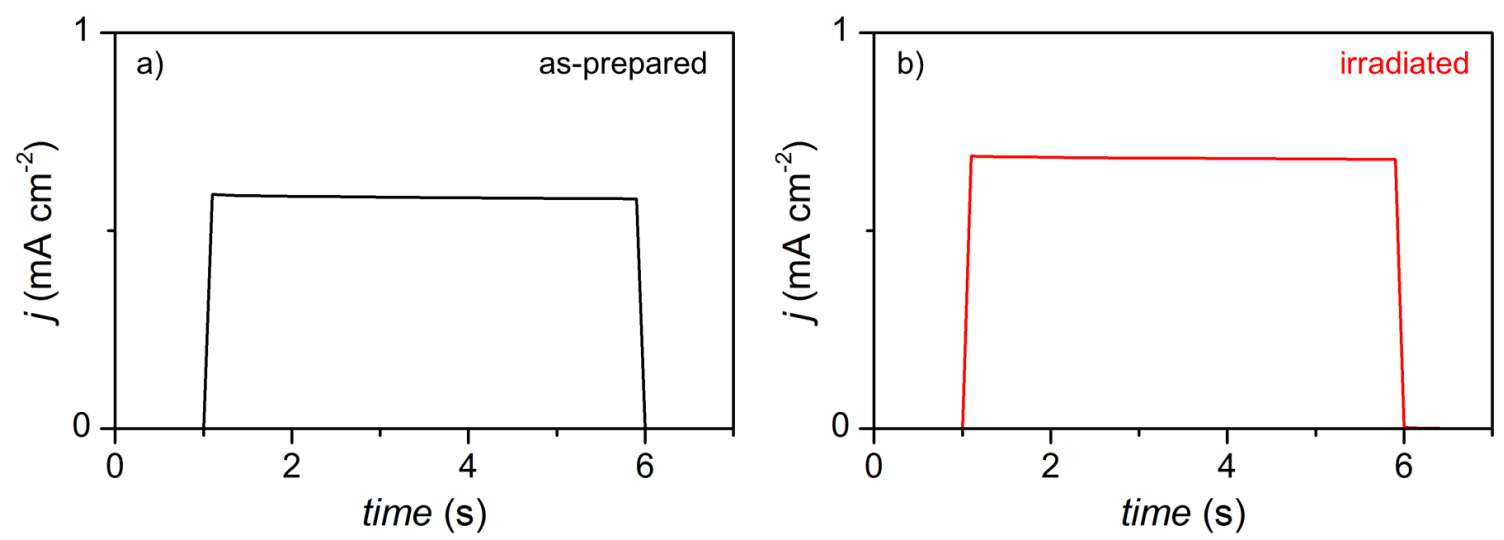

Figure S10 Photocurrent transients measured in KPi solution at $1.23 \mathrm{~V}$ vs. RHE of $\mathrm{WO}_{3}$ before (a) and after (b) UV irradiation.

Table S1 Relative Contents of $\mathrm{W}$ and O Atoms at the Surface Before and After $4 \mathrm{~h} \mathrm{UV}$ Irradiation. Values Correspond to Integration of the Relevant XPS Peaks.

\begin{tabular}{cccc}
\hline UV irradiation time & Atom \% of W $\mathbf{4} \boldsymbol{f}$ & Atom\% of O 1s & Ratio of O:W \\
\hline $\mathbf{0 ~ h}$ & 17.94 & 48.34 & 2.69 \\
\hline $\mathbf{4}$ h & 18.28 & 48.97 & 2.68 \\
\hline
\end{tabular}

Table S2 PEC OER Current Densities Measured at $1.23 \mathrm{~V}$ vs RHE Before and After UV Irradiation for Three Independently Prepared Samples. (Sample 1 is Shown in Figure 2.)

\section{UV irradiation time $\quad$ Sample 1 $\quad$ Sample 2 $\quad$ Sample 3}

$\begin{array}{cccc}\text { 0 h } & 0.53 \mathrm{~mA} / \mathrm{cm}^{2} & 0.51 \mathrm{~mA} / \mathrm{cm}^{2} & 0.48 \mathrm{~mA} / \mathrm{cm}^{2} \\ \mathbf{4 h} & \begin{array}{c}0.69 \mathrm{~mA} / \mathrm{cm}^{2} \\ \text { (increased by } 30 \%)\end{array} & \begin{array}{c}0.68 \mathrm{~mA} / \mathrm{cm}^{2} \\ \text { (increased by } 33 \% \text { ) }\end{array} & \begin{array}{c}0.61 \mathrm{~mA} / \mathrm{cm}^{2} \\ \text { (increased by } 27 \% \text { ) }\end{array}\end{array}$

\section{Reference}

(1) Su, J.; Guo, L.; Bao, N.; Grimes, C. A. Nano Lett. 2011, 11, 1928-1933.

(2) Li, T.; He, J.; Peña, B.; Berlinguette, C. P. Angew. Chem. 2016, 55, 1769-1772. 